\title{
Presencia de anticuerpos contra Leptospira spp en hogares con felinos y humanos en un barrio de Medellín, Colombia
}

\author{
Presence of antibodies against Leptospira spp in homes with cats and humans in a \\ neighbourhood of Medellín, Colombia
}

\author{
Daniela Isaza Molina ${ }^{1,4}$, Héctor Bayron Agudelo², Erica Tatiana Loaiza ${ }^{3}$
}

\section{Resumen}

Este estudio pretendió identificar la presencia de anticuerpos contra Leptospira spp en felinos y humanos convivientes del barrio Nueva Villa de La Iguaná, de la Comuna 7 de Medellín, Colombia, entre noviembre y diciembre de 2018. Datos históricos de la zona indican una seroprevalencia de $63.2 \%$ en humanos. Mediante un estudio transversal en el barrio, se seleccionaron 30 hogares donde convivían 30 personas y 32 felinos. Se les aplicó una encuesta y se tomaron muestras de sangre para detectar anticuerpos contra Leptospira spp mediante la prueba de microaglutinación (MAT). Los resultados de serorreacción contra Leptospira spp en felinos y humanos fueron negativos a leptospirosis, lo que sugiere que los felinos del barrio tienen un rol protector contra la Leptospira spp en sus dueños.

Palabras clave: felinos, leptospirosis felina, leptospirosis humana, microaglutinación

\section{AbSTRACT}

This study aimed to identify the presence of antibodies against Leptospira spp in felines and humans living in the same house of the Nueva Villa de La Iguaná neighborhood, part of the Comuna 7 of Medellín, Colombia, between November and December 2018. Historical data from the area indicate a seroprevalence of $63.2 \%$ in humans. Through a cross-sectional study in the neighborhood, 30 homes were selected where 30 people and 32 cats lived together. A survey was applied, and blood samples were collected to detect

\footnotetext{
${ }^{1}$ Universidad de Antioquia, Colombia

${ }^{2}$ Facultad Nacional de Salud Pública, Universidad de Antioquia, Colombia

${ }^{3}$ Universidad Pontificia Bolivariana y Universidad CES, Colombia

${ }^{4}$ E-mail: daniela.isaza@udea.edu.co
}

Recibido: 1 de octubre de 2019

Aceptado para publicación: 25 junio de 2020

Publicado: 11 de agosto de 2020 
antibodies against Leptospira spp using the microagglutination test (MAT). The seroreactive results against Leptospira spp in cats and humans were negative for leptospirosis, which suggests that the felines in the neighborhood have a protective role against Leptospira spp in their owners.

Key words: felines, feline leptospirosis, human leptospirosis, microagglutination

\section{INTRODUCCIÓN}

La leptospirosis es una enfermedad zoonótica de distribución mundial, frecuente en regiones tropicales y subtropicales, donde aparece durante todo el año en áreas rurales y urbanas (Desachy, 2006). Es una de las zoonosis más difundidas causada por espiroquetas del género Leptospira, el cual incluye numerosos serovares que pueden ser liberados por animales domésticos y silvestres infectados, principalmente roedores (Desachy, 2006; Morales, 2012). Las leptospiras son transmitidas entre animales y humanos por contacto directo (orina infecta$\mathrm{da}$, secreciones) y de forma indirecta al ingerir agua y alimentos contaminados (Morales, 2012; Azocar-Aedo et al., 2014).

La enfermedad en el humano puede presentarse desde leve hasta llegar a ser mortal, produciendo una sintomatología clínica muy variada y, a su vez, confundida con otras enfermedades endémicas como dengue, zika u otros virus estacionales (Céspedes, 2002). Los estudios de seroprevalencia en Colombia (Agudelo-Flórez y Restrepo Isaza, 2007) han permitido conocer la frecuencia de la enfermedad en ciertas áreas del país, ya que es considerada como una enfermedad de notificación obligatoria (Ministerio de Salud y Protección Social, 1986). Estos estudios se han enfocado principalmente en humanos que viven en zonas rurales (AgudeloFlórez et al., 2007; Yusti et al., 2012; Rodríguez Villamarín, 2014), y su efecto en la salud animal, especialmente en bovinos, porcinos, caninos y roedores, para determinar si la relación hombre-animal es un factor de riesgo de contraer y diseminar la enfermedad (Agudelo-Flórez et al., 2010; Arcila Quiceno, 2011; Morales, 2012). Sin embargo, no se conoce la relación con otros animales como los gatos.

Considerando que existen grandes vacíos de conocimiento sobre la transmisión de Leptospira spp entre especies que viven en las ciudades, y siendo los gatos una de las mascotas más populares, se requiere conocer la prevalencia de la infección. Los estudios realizados sobre felinos en el ámbito de las ciudades se han enfocado en felinos silvestres de los zoológicos (Jiménez-Nicholls et al., 2009). Estudios en otras partes del mundo han demostrado que los gatos pueden adquirir la bacteria y eliminarla en orina hasta por cuatro semanas pos-infección, convirtiéndose en reservorios de algunas serovariedades de Leptospira como $L$. icterohaemorragiae, L. pomona, $L$. bratislava, L. hardjo y L. automnalis, que son potencialmente patógenas para los humanos, pero que el gato, en la mayoría de casos, no presenta síntomas clínicos de enfermedad (Morales, 2012; Azocar-Aedo et al., 2014; Rodriguez et al., 2014). Debido a esto, el objetivo del presente estudio fue identificar la presencia de anticuerpos contra Leptospira spp en gatos de Medellín, y conocer si la relación entre el gato y su dueño puede convertirse en un factor protector $o$ causal de la enfermedad en los humanos. 


\section{Materiales y Métodoos}

El proyecto de investigación se desarrolló en la Comuna 7 de la ciudad de Medellín, Colombia, entre noviembre y diciembre de 2018. Esta comuna fue elegida debido a que, según datos de una investigación realizada con la Secretaria de Salud de Medellín en 2015, utilizando la técnica de Microaglutinación (MAT), es uno de los lugares con mayor seropositividad a Leptospira en roedores $(40 \%)$.

De los barrios que conforman la Comuna 7, se eligió Nueva Villa de La Iguaná, dadas sus condiciones topográficas y la cercanía a la subcuenca de la quebrada La Iguaná, que lo convierten en una zona con mayor riesgo potencial de presencia y permanencia de Leptospira spp por la humedad de la zona y por la presencia de roedores. Loaiza et al. (2015) indica que el barrio presenta $70 \%$ de seropositividad en roedores, $25 \%$ en caninos con esquema de vacunación incompleto y $63.2 \%$ en humanos. Por estratificación socioeconómica predominan los estratos 1,2 y 3 (DANE, 1994) con población afrodescendientes, raizales y mestizos, entre otros, provenientes de diferentes lugares del municipio, ya sea por desplazamiento voluntario o forzado. Las viviendas están construidas con adobe o madera, según ingresos de las familias, viéndose construcciones de 2-3 pisos que pertenecen a diferentes núcleos familiares. El barrio cuenta, en su gran mayoría con alumbrado y servicios públicos domiciliarios.

El principal criterio de inclusión fue que las personas y sus felinos convivieran en el mismo hogar por un mínimo por seis meses, sin importar raza o sexo, y las personas deberían tener más de 18 años y que la persona entrevistada fuera la que más contacto tuviera con el felino. Se excluyeron los felinos y humanos que presentaron algún tipo de patología que no permitiera la extracción de una muestra de sangre, además de personas que no desearon facilitar la toma de muestras de sangre.
Para la realización de la investigación se contó con la aprobación del Comité de Ética de la Facultad Nacional de Salud Pública de la Universidad de Antioquia y el Comité de Ética para la Experimentación con Animales de la Sede de Investigación Universitaria (SIU) de la Universidad de Antioquia, Colombia.

El equipo investigador realizó un recorrido por el barrio haciendo un conteo de la población felina del barrio. Se determinaron las características de los hogares, las personas y los gatos mediante visitas y se les asignó un código de identificación para su seguimiento.

El equipo investigador realizó un recorrido por el barrio haciendo un conteo de la población felina, ya que se desconocía el número exacto debido a que la información suministrada por la Secretaria de Salud de Medellín presentaba incongruencias sobre la ubicación de los felinos. Posteriormente, se concertaron visitas donde se determinaron las características de los hogares, de las personas y de los gatos, asignándoles un código de identificación para su seguimiento. Dado el reducido número de participantes, no se calculó el tamaño mínimo muestral.

Se recolectaron muestras de sangre en los felinos y los humanos para determinar la presencia o ausencia de anticuerpos contra Leptospira mediante la prueba de microaglutinación (MAT) para las siguientes serovariedades en el humano: L. patoc, $L$ icterohaemorrhagiae, L. grippothyphosa, L. pomona, L. canicola. L. hardjo, $L$. ballum, L. bratislava, L. santarosii, $L$. tarassovi, $L$. pyrogenes) y en los felinos: $L$. icterohaemorrhagiae, L. grippothyphosa, L. pomona, L. canicola. L. hardjo, L. ballum, L. bratislava, L. tarassovi, $L$. pyrogenes).

Las muestras de sangre se obtuvieron mediante venopunción de la vena cefálica en tubos vacutainer, que fueron rotulados con el 
Cuadro 1. Características de las viviendas del barrio Nueva Villa de la Iguaná

\begin{tabular}{|c|c|}
\hline Características & $\%$ \\
\hline Tienen acueducto & 100.0 \\
\hline $\begin{array}{l}\text { Pasa el vehículo recolector de } \\
\text { basura }^{1}\end{array}$ & 100.0 \\
\hline Presencia de agua estancada & 100.0 \\
\hline $\begin{array}{l}\text { A menos de } 100 \mathrm{~m} \text { de } \\
\text { quebradas }\end{array}$ & 80.0 \\
\hline $\begin{array}{l}\text { A menos de } 100 \mathrm{~m} \text { de acopio } \\
\text { de basura }\end{array}$ & 36.7 \\
\hline $\begin{array}{l}\text { Vías de ingreso para roedores } \\
\text { en viviendas }\end{array}$ & 90.0 \\
\hline Presencia de roedores & 90.0 \\
\hline $\begin{array}{l}\text { Otra mascota diferente al } \\
\text { gato }^{2}\end{array}$ & 36.7 \\
\hline
\end{tabular}

código del hogar y la letra $\mathrm{H}$ (Humano) o $\mathrm{F}$ (felino), respectivamente. Las muestras de sangre se colocaron en una nevera portátil refrigerada, y al finalizar el día se realizó la extracción del suero, que fue almacenando a $-20{ }^{\circ} \mathrm{C}$. Al finalizar la fase de muestreo, los sueros fueron llevados al laboratorio del Instituto Colombiano de Medicina Tropical (ICMT) de la Universidad del CES.

El análisis de la información se realizó con ayuda del software estadístico de IBM Statistical Package for Social Sciences ${ }^{\circledR}$ v. 21 (SPSS), empleando estadística descriptiva de acuerdo con la distribución de los datos de cada variable en estudio, las cuales se agruparon según características locativas y físicas de las viviendas, características de los humanos (edad, sexo, actividad económica, tenencia de otras mascotas, hábitos higiénicos, almacenamiento de alimentos, entre otras), características de los felinos (edad, sexo, estado sanitario, cazador, hábitos callejeros, uso de caja de arena) y resultado de las MAT.

\section{Resultados}

El trabajo se realizó con 30 personas con felinos, que accedieron a participar en el estudio. En dos hogares, los dueños tenían dos felinos y solicitaron que se incluyera en el muestreo a los dos animales, por lo cual la población de felinos fue de 32 .

En el caso de las personas, se obtuvo la participación mayoritaria de mujeres (76.7\%) en comparación a los hombres (23.3\%). Los datos de la edad siguieron una distribución normal (Shapiro-Wilk, $\mathrm{p}=0.25$ ), presentado una media de 47.3 años con un intervalo de confianza del $95 \%$ entre 40.5 y 54.2 una mediana de 47.5 y una desviación típica de 18.4 años.

El 46.7\% de las personas solo tenía estudios concluidos de primaria, seguido por el $40 \%$ con estudios de secundaria y $13.3 \%$ con estudios a nivel técnico. La actividad más predominante en los encuestados fue ser ama de casa $(46.7 \%)$, seguido del ser comerciante $(13.3 \%)$. El $23.3 \%$ de los hogares reportan la costumbre de dejar alimentos expuestos en la noche; así asimismo, con relación al lavado de alimentos como frutas, verduras y enlatados se reporta que la mayoría acostumbran a lavarlos $(53.3 \%)$.

Desde las características locativas o físicas de las viviendas, se observó una buena cobertura de servicios públicos domiciliarios, pero deficiencias en características que favorecen la presencia de roedores en los alrededores (Cuadro 1).

En los felinos se ve una proporción más equilibrada entre los machos $(40.6 \%)$ y hembras (59.4\%), y según la edad, se determinó que siguen una distribución normal (ShapiroWilk, $\mathrm{p}=0.00$ ), con una mediana de 36 meses $\mathrm{y}$ un rango intercuartil de 48 . 
El $66.7 \%$ de los hogares tenían un solo gato, $26.7 \%$ tenía dos y $6.6 \%$ tenía tres gatos. El $71.9 \%$ de los felinos estaba esterilizado y el $90.6 \%$ vacunado, pero de estos últimos, el $68.8 \%$ solo tenía la vacuna antirrábica y el $9.4 \%$ reportaba un esquema completo de vacunación (triple felina, leucemia y rabia).

El $71.9 \%$ de los gatos salían a la calle en mayor o menor medida. Los encuestados manifestaron que $65.6 \%$ de los felinos cazaban, $28.1 \%$ lo hacían algunas veces y $6.3 \%$ no tenían hábitos cazadores o nunca los habían visto cazando. Entre los felinos cazadores, el 70\% atrapa mayormente roedores, y algunas veces lagartijas, insectos y aves. Asimismo, el 43.8\% de los felinos solo mata a las presas, pero no las come.

Dentro del uso de la bandeja sanitaria (caja de arena), el $40.6 \%$ de los felinos la usan, $3.1 \%$ la usa a veces, y el $56.3 \%$ no tienen caja de arena en sus viviendas, por lo que el lugar más común donde el gato realiza sus deposiciones es lejos de la casa (46.9\%). De los que reportaron tener bandeja sanitaria dentro de las viviendas, $40.6 \%$ se lavan las manos luego de asearlas y el $3.1 \%$ no lo hacen.

Los resultados del MAT en humanos y felinos fueron negativos. No se dieron reacciones aglutinantes dentro de las muestras, lo que se traduce como un resultado negativo para las serovariedades en las cuales se corrió la prueba.

\section{Discusión}

Este estudio es el primero, del que se tiene conocimiento, realizado en la ciudad de Medellín con felinos domésticos y sus dueños, que pretendió identificar la posible presentación de anticuerpos contra Leptospira spp dentro de las ciudades y, específicamente si existe alguna relación de contagio entre el gato y su dueño, lo cual podría brindar herramientas para conocer la epidemiología de la leptospirosis en felinos, y ofrecer a los entes de control mecanismos que permitan realizar una mejor vigilancia epidemiológica para este tipo de enfermedades reemergentes.

En el presente estudio, tanto los felinos como sus dueños presentaron reacciones negativas para los serovares de Leptospira spp evaluados mediante la prueba de MAT, prueba que es considerada como la prueba de oro para la identificación de las serovariedades de Leptospira spp a nivel mundial (Instituto Nacional de Salud, 2014; Mora, 2017). Sin embargo, es una técnica con limitaciones para su ejecución e interpretación. En diversos estudios se encuentra que el rango de corte para catalogar la positividad de una muestra es de >1:100 (Azócar-Aedo et al., 2014; Jamshidi et al., 2009; Markovich et al, 2012; Morales, 2012; Obrenoviæ et al., 2015; Pratt et al., 2017; Talebkhan Garoussi et al., 2015) y no de >1:200 como se maneja en felinos para el ICMT.

Si bien Loaiza et al. (2015) detectaron seropositividad a Leptospira spp en humanos y en roedores capturados en el barrio, y que Barragan et al. (2017) demuestran la gran cantidad de bacterias de Leptospira spp que pueden excretar los roedores en su orina, no se llegó a encontrar casos positivos en el presente estudio. En parte, podría ser explicado porque se reporta una baja seropositividad en felinos domésticos (Azócar-Aedo et al., 2014; Jamshidi et al., 2009; Markovich et al., 2012; Morales, 2012; Obrenoviæ et al., 2015; Pratt et al., 2017; Talebkhan Garoussi et al., 2015).

Por otro lado, se estima que en humanos la seropositividad a nivel local va entre 6\% (Agudelo-Flórez et al., 2007; Romero Peñuela et al., 2011) y 67.9\% (Rodríguez et al., 2009). Sin embargo, estas investigaciones, aunque comparten algunos factores de riesgo físicos con la población de humanos estudiada, no llegaría a ser un referente para indicar que una investigación realizada en la ciudad de Medellín diera resultados simila- 
res, lo que lleva a la gran diferencia de seropositividad encontrada.

Una explicación plausible a las reacciones negativas a Leptospira spp, es que el $76.7 \%$ de las personas muestreadas eran mujeres, ya que según diversos autores (Navarrete et al., 2000; Rivas, 2013; Ferro et al., 2006; Romero et al., 2010), se encuentra un predominio de la enfermedad en hombres, dada su relación las actividades económicas desarrolladas por ellos, que en algunos casos puede aumentar el riesgo de contacto con la bacteria. Dado este panorama, se puede argüir el rol protector de las mujeres, ya que el $46.7 \%$ de ellas eran amas de casa, rol considerado por Azócar-Aedo et al. (2014), Rodríguez (2014) y Navarrete et al., (2000) como de bajo riesgo ocupacional de presentación de la leptospirosis; más aún que en todos los casos, pese a tener bajos ingresos económicos, los hogares mantienen buenas condiciones higiénicas. Aun así, este hallazgo no concuerda con lo encontrado por Rodríguez et al. (2009), quienes hallaron presencia de anticuerpos en amas de casa.

En la presentación de resultados negativos en los felinos se podría explicar por la relación de varios factores. El 71.9\% estaba esterilizado, por lo que comportamientos como el marcaje de territorio y la caza de roedores para alimentar crías (Morris, 1988) no estaba presente; la mayor parte de los gatos eras hembras y según Talebkhan et al. (2015) son los machos los que más presentan anticuerpos contra Leptospira spp. Asimismo, según Sprißler et al. (2018), felinos mayores de cuatro años son más propensos a infectarse, y en el caso del presente estudio, el promedio de edad de los felinos muestreados fue de tres años. Por otro lado, si bien el $72.1 \%$ salía a la calle, la mayoría lo hacía solo para realizar sus deposiciones, lo que según Jamshidi et al. (2009) y Hartmann et al. (2013) puede considerarse un rasgo protector, ya que los gatos tienen un hogar.
La encuesta indicó que el 93.7\% de los felinos tenían hábitos cazadores y que los roedores eran sus principales presas. Sin embargo, Azócar-Aedo et al. (2014) indican que felinos de los entornos urbanos con hábitos cazadores presentaron bajos niveles de anticuerpos contra Leptospira spp (1.8\%). En este estudio, era común que los gatos matasen a su presa, pero no se la comiesen; es decir, cazaban más por instinto predador que por necesidad de alimentarse, como lo tendría que hacer un gato callejero. Según Truong et al. (2013), el no comerse los roedores ayudaría a disminuir el riesgo de contagio directo. Por otro lado, los resultados de la investigación apoyan la tesis expuesta por Childs et al. (1992) sobre el rol protector de los felinos en entornos urbanos hacia sus dueños

No se puede concluir que los felinos domésticos caseros tengan el 100\% de efectividad como controlador de la leptospirosis en sus dueños, pero se podría especular que tener un gato cumple un rol protector, dados los resultados obtenidos. Tampoco se puede concluir que a los felinos de Medellín no les da leptospirosis, pero se podría pensar en la hipótesis que los felinos del barrio Nueva Villa de La Iguaná han evolucionado genéticamente para que su sistema inmunológico combata las bacterias de Leptospira spp, como lo sugieren Obrenoviæ et al. (2015) y Pratt et al. (2017), quienes indican que la ausencia de desarrollo de signos clínicos en los gatos puede ser el resultado de alguna adaptación genética en ellos, dadas por las condiciones climáticas o por el tener un hogar.

Los resultados generales obtenidos llevan a concluir que, específicamente en el barrio Nueva Villa de La Iguaná de Medellín, no se evidencia una circulación de anticuerpos contra Leptospira spp en los felinos y humanos convivientes que hicieron parte de la investigación, a su vez que, dados los resultados negativos, no se pudieron identificar factores asociados con el contagio de Leptospira spp en felinos y sus dueños. Los hallazgos 
sugieren que la relación evolutiva entre humanos y felinos no solo se queda en una relación de protección y compañía suministrada por el gato hacia el hombre, sino que esa relación evoluciona hasta el punto de que el felino sirve como protección física contra roedores y contra la leptospirosis que puede ser transmitida por ellos, y a su vez el hombre, al considerar al gato como una mascotas que debe ser cuidada y alimentada, lo protege contra el contagio directo de la leptospirosis, creando una relación simbiótica de protección mutua entre humanos y felinos domésticos.

\section{Literatura Citada}

1. Agudelo-Flórez P, Arango JC, Merizalde E, Londoño AF, Quiroz VH, Rodas JD. 2010. Evidencia serológica de circulación de Leptospira spp en Rattus norvegicus naturalmente expuestos en una zona urbana colombiana. Rev Salud Pública 12: 990-999.

2. Agudelo-Flórez P, Jaramillo RBN, Arboleda NM. 2007. Situación de la leptospirosis en el Urabá antioqueño colombiano: estudio seroepidemiológico y factores de riesgo en población general urbana. Cad Saude Publica 23: 20942102. doi: 10.1590/S0102-311X2007000900017

3. Agudelo-Flórez P, Restrepo M. 2007. Frecuencia de anticuerpos para 14 serovariedades de Leptospira spp detectados por la prueba de microaglutinación en una serie de casos humanos de Antioquia, Colombia. Rev CES Medicina 21:7-13.

4. Arcila Quiceno VH. 2011. Prevalencia de infección por Leptospira spp en animales domésticos que representan contacto de riesgo para humanos en el área metropolitana de Bucaramanga y Lebrija, Colombia. Tesis de Maestría. Colombia: Univ. de Antioquia. $166 \mathrm{p}$.

5. Azócar-Aedo L, Monti G, Jara R. 2014. Leptospira spp in domestic cats from different environments: prevalence of antibodies and risk factors associated with the seropositivity. Animals 4: 612626. doi: 10.3390/ani4040612

6. Barragan V, Nieto N, Keim P, Pearson T. 2017. Meta-analysis to estimate the load of Leptospira excreted in urine: beyond rats as important sources of transmission in low-income rural communities. BMC Res Notes 10: 71. doi: 10.1186/s13104-017-2384-4

7. Céspedes M. 2002. Leptospirosis: enfermedad zoonótica reemergente. Rev Peru Med Exp Salud Publica, 22: 290-307.

8. Childs JE, Schwartz BS, Ksiazek TG, Graham RR, LeDuc JW, Glass GE. 1992. Risk factors associated with antibodies to leptospires in inner-city residents of Baltimore: a protective role for cats. Am J Public Health Res 82: 597 599. doi: 10.2105/AJPH.82.4.597

9. DANE. 1994. Estratificación socioeconómica para servicios públicos domiciliarios. [Internet]. Disponible en: https:// www.dane.gov.co/index.php/serviciosal-ciudadano/servicios-informacion/ estratificacion-socioeconomica \#preguntas-frecuentes

10. Desachy F. 2006. Zoonosis con manifestaciones generales. In: Las zoonosis transmisión de las enfermedades de los animales al ser humano. Barcelona: Ed De Vecchi. p 74-76.

11. Ferro BE, Rodríguez $A L$, Pérez $M$, Traveis BL. 2006. Seroprevalencia de infección por leptospirosis en barrios periféricos de Cali. Biomédica 26: 250257. doi: $10.7705 /$ biomedica.v26i2.1414

12. Hartmann K, Egberink H, Pennisi MG, Lloret A, Addie D, Belák S, Boucraut-Baralon C, et al. 2013. Leptospira species infection in cats. $\mathrm{J}$ Feline Med Surg 15: 576-581. doi: 10.1177/1098612x13489217

13. Instituto Nacional de Salud. 2014. Protocolo de vigilancia en Salud Pública. Leptospirosis. Colombia. [Internet[. Disponible en: http://www.dadiscartagena.gov.co/images/docs/saludpublica/vigilancia/protocolos/pro_leptospirosis_-2014.pdf 
14. Jamshidi S, Akhavizadegan M, Maazi N, Ali AG, Bokaie S. 2009. Serologic study of feline leptospirosis in Tehran, Iran. Iran J Microbiol 1: 32-36.

15. Jiménez-Nicholls L, Perez J, Loaiza J, Ocampo M, Agudelo-Flórez P. 2009. Determinación de la frecuencia de leptospirosis en felinos y primates del Parque Zoológico Santa Fé, Medellín, Colombia. Rev CES Med Vet 4: 39-47. doi: $10.21615 / 951$

16. Loaiza-Echeverry E, Hincapié-Palacio D, Ochoa J, Ospina J. 2015. Leptospirosis risk around a potential source of infection. Smart Biomed Physiol Sensor Technol 12: 9487. doi: 10.1117/12.2177008

17. Markovich JE, Ross L, McCobb E. 2012. The prevalence of leptospiral antibodies in free roaming cats in Worcester County, Massachusetts. J Vet Intern Med 26: 688-689. doi: 10.1111/j.19391676.2012.00900.x

18. Mora RA. 2017. Leptospirosis en Costa Rica. Técnicas diagnósticas y su tratamiento. Rev Enf Emerg 16: 23-29.

19. Morales A. 2012. Prevalencia de Leptospirosis en perros y gatos de predios lecheros del sur de Chile. Tesis de Médico Veterinario. Valdivia, Chile: Univ. Austral de Chile. 25 p.

20. Morris D. 1988. Observe a su gato. Barcelona: Plaza \& Janes Ed. 117 p.

21. Navarrete J Acevedo JA, Huerta E, Torres J, Gavaldón DG 2000. Prevalencia de anticuerpos contra dengue y leptospira en la población de Jáltipan, Veracruz. Salud Publica Mex 42:288-297.
22. Obrenoviae $S$, Vakanjac S, Bogunoviae D, Steviae N, Valèia M, Radojièia $S$. 2015. Seroprevalence of cat leptospirosis in Belgrade (Serbia). Acta Vet (Beogr) 64: 510-518. doi: 10.2478/acve2014-0047

23. Pratt N, Conan A, Rajeev S. 2017. Leptospira seroprevalence in domestic dogs and cats on the Caribbean Island of Saint Kitts. Vet Med Int 2017: 5904757. doi: $10.1155 / 2017 / 5904757$

31. [SUIN] Sistema Único de Información Normativa. 1986. Decreto 2257 de 1986. [Internet]. Disponible en: http:// www.suin-juriscol.gov.co/viewDocument.asp?ruta=Decretos/1426755

32. Talebkhan Garoussi M, Mehravaran M, Abdollahpour G, Khoshnegah J. 2015. Seroprevalence of leptospiral infection in feline population in urban and dairy cattle herds in Mashhad, Iran Vet Res Forum 6: 301-304.

33. Truong QL, Seo TW, Yoon BI, Kim HC, Han JH, Hahn TW. 2013. Prevalence of swine viral and bacterial pathogens in rodents and stray cats captured around pig farms in Korea. J Vet Med Sci 75: 1647-1650. doi: 10.1292/jvms.12-0568

34. Yusti D, Arboleda M, Agudelo-Flórez P. 2012. Factores de riesgo sociales y ambientales relacionados con casos de leptospirosis de manejo ambulatorio y hospitalario, Turbo-Colombia. Biomédica 33: 117-129. doi: 10.7705/biomedica.v33i0.1457 